\title{
Network-Aware Multi-Agent Simulations of Herder-Farmer Conflicts
}

\author{
Henry K. Dambanemuya* \\ Department of Communication Studies \\ Northwestern University \\ Evanston, USA \\ hdambane@u.northwestern.edu
}

\author{
Emőke-Ágnes Horvát \\ Department of Communication Studies \\ Northwestern University \\ Evanston, USA \\ a-horvat@northwestern.edu
}

\begin{abstract}
We propose a network-aware multi-agent simulation approach to understanding the interlacing connections between herder-farmer communities in open property regimes. Specifically, we model herder-farmer conflicts in agent-based terms whereby individual decision-making, pastoral mobility, and symbiotic herder-farmer relations result in the emergence of a complex adaptive system in which communal resources are managed in ways that either lead to peaceful coexistence or conflict. From a theoretical perspective, we hope to further understanding of how individual decision-making and coordination produces complex adaptive systems as well as how emergent structures shape individual action. In practice, we anticipate that this study will help shed light on how herder-farmer communities can cooperate and coordinate their activity and mobility patterns to manage common pool resources in sustainable ways that mitigate violent conflict. Broadly, our work aims to contribute new insights towards multi-agent modelling of traditional small-scale societies.
\end{abstract}

Index Terms-Multi-Agent Simulations, Social Networks, Peacebuilding

\section{INTRODUCTION}

Pastoral conflicts-expressed struggles between herders and farmers who perceive incompatible goals, scarce resources, and interference from one another in achieving their goalshave crucial implications for communities living in SubSaharan Africa. Recent changes in land use and water availability due to population growth, erratic weather patterns that accompany climate change, and increased desertification have resulted in outbursts of violent conflict between herder-farmer communities. Since it is difficult to substantiate that such violence is on the rise or increasing in intensity [2], it is reasonable to believe that the modal state of herder-farmer

The authors would like to thank Orsolya Vaśaŕhelyi and Brett O'Bannon for their feedback. This work was partially funded by the U.S. National Science Foundation under Grant No. IIS-1755873.

* Corresponding author.

Permission to make digital or hard copies of all or part of this work for personal or classroom use is granted without fee provided that copies are not made or distributed for profit or commercial advantage and that copies bear this notice and the full citation on the first page. Copyrights for components of this work owned by others than ACM must be honored. Abstracting with credit is permitted. To copy otherwise, or republish, to post on servers or to redistribute to lists, requires prior specific permission and/or a fee. Request permissions from permissions@acm.org

ASONAM '19, August 27-30, 2019, Vancouver, Canada

(C) 2019 Association for Computing Machinery.

ACM ISBN 978-1-4503-6868-1/19/08/ $\$ 15.00$

http://dx.doi.org/10.1145/3341161.3343682 relations is located on a conflict-symbiosis continuum, the condition at any given moment determined by a conflux of endogenous and exogenous factors that we seek to explore. Building upon previous research [4] that demonstrates that not all herder-farmer disputes occurring under the same structural conditions escalate into widespread violence, our research questions proceed as follows:

1) Why do some herder-farmer conflicts escalate into violent outbursts whereas others are peacefully resolved?

2) Can we identify herder-farmer interaction patterns or network structures that lend themselves more readily to conflict escalation? Which interaction patterns facilitate de-escalation?

3) Are there community structures, institutional features, or ecological factors that determine the outcomes of herderfarmer conflicts.

To probe into these questions, we propose a networkbased multi-agent simulation approach to understanding the interlacing connections between herders and farmers and their patterns of conflict. Specifically, we aim to model herderfarmer conflicts in an agent-based approach where individual decision-making, pastoral mobility, and symbiotic herderfarmer relations result in the emergence of a complex adaptive system in which communal resources are managed in ways that either lead to peaceful coexistence or conflict.

\section{Proposed Work}

The common narrative on herder-farmer conflicts claims that recent changes in land use, erratic weather patterns that accompany climate change, and increased desertification have resulted in changes in farming and nomadic activities as herders seasonally migrate in search of suitable grazing lands and farmlands expand into areas traditionally used for grazing and as migratory corridors. At the same time, changes in farming activities as farmers begin to raise their own cattle and use commercial fertilisers instead of organic manure have weakened relational ties between herders and farmers. These changing dynamics in herder-farmer community interactions have further intensified competition for key scarce resources such as watering areas, wetlands, fertile lands, grazing lands, shores, riverbeds, and campsites. Based on this common narrative, we utilise network modelling and analysis techniques 


\section{IEEE/ACM International Conference on Advances in Social Networks Analysis and Mining}

to investigate interaction outcomes of herder-farmer social networks generated through different theoretical mechanisms. The network models incorporate crucial dependencies between herder-farmer communities such as social support, collective and self-interest, as well as material exchange and resource dependence.

Model Specification: The basic principle of our model is that varying the initial theoretical generative mechanism of herder-farmer network tie formation results in different patterns of emergent behaviour. The emergent property we are interested in is outbursts of violent conflict between herder and farmer agents with competing objective functions. The objective of herder agents is to find suitable grazing pastures for their cattle while farmers seek to increase their crop yield. Farmer agents occupy environment patches of increasing size to reflect the expansion of farmlands into areas traditionally used as grazing lands and pastoral migratory routes. We model this phenomenon using an environment rule. A movement rule models a common practice of transhumance whereby nomadic herders seasonally migrate their livestock. After each time step, herders either remain in their current location or move to a new location based on the movement rule. The time cycles consist of nomadic herder activity and violent clashes with farmers. At each time step, every agent observes a state, chooses an action, and transitions to a new state taking into account key parameters shown in Table I. A simple agent rule describes agent state transitions between violent $(V)$ and peaceful $(P)$ co-existence:

$$
\begin{cases}V, & \text { if }\left(C_{p}+H\right)-\left(C_{o}+S\right)>\text { threshold } \\ P, & \text { otherwise }\end{cases}
$$

TABLE I

AGENT PARAMETERS

\begin{tabular}{|l|l|l|}
\hline Description & Parameter Name & Values \\
\hline$H$ & Economic Hardship & 1.0 \\
\hline$C_{o}$ & Cooperation & $\sim U(0,1)$ \\
\hline$C_{p}$ & Competition & $1-C_{o}$ \\
\hline$D$ & Conflict Duration & $\sim U\left(0, D_{\max }\right)$ \\
\hline$S$ & Tie Strength & $\sim U(0,1)$ \\
\hline$(x, y)$ & Agent position in space & $([-30,30],[-20,20])$ \\
\hline Agent State & P, V & Peaceful, Violent \\
\hline
\end{tabular}

Simulations: Each simulation begins with a herder-farmer social network located on a 2D landscape where herders follow a seasonal transhumance mobility pattern in search of key resources such as grazing lands and water. For each herder-farmer network topology, we observe the frequency of outbursts of violent conflict after a given number of time steps while varying the network's properties. For example, to test a simple null model whereby herder-farmer social ties are randomly generated through an Erdős-Rényi random process, we vary agents' cooperation and tie strength while keeping the rest of the parameters constant. Then, we observe and compare the total number of outbursts of violent conflict after 10,000 time steps as shown in Figure 1

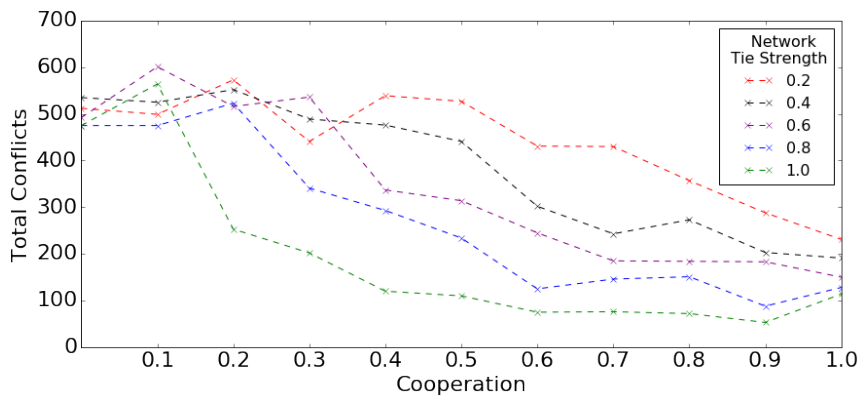

Fig. 1. Total number of conflicts observed from Erdős-Rényi herder-farmer social networks of 100 farmers and 200 herders while varying individual agent cooperation and herder-farmer tie strength and using a threshold of 0.8 .

Objective: A particular objective of our model is to establish sets of conditions expressed in terms of the model's network parameters and structural properties that explain the emergence of violence thereby providing a test-bed to evaluate existing theories of conflict. The proposed work seeks to provide a conceptual characterisation of macro-level herderfarmer conflicts as emergent phenomena of a complex adaptive system resulting from simple interaction rules between microlevel agents (herders and farmers) and meso-level ecological factors. Relying on Gidden's theory of structuration [1], which posits that socio-ecological systems are both mediums and outcomes of the practices they recursively organise, we further seek to examine the duality of individual decision-making and emergent phenomena.

Empirical Data: To the extent possible, we rely on empirical data from [3] and [5] to derive model parameters, formulate, and validate mobility and interactions patterns.

Implications: We anticipate that this study will help shed light on how herder-farmer communities can cooperate and coordinate their activity and mobility patterns to manage common pool resources in sustainable ways that mitigate violent conflict. Broadly, our work aims to contribute new insights towards multi-agent modelling of traditional smallscale societies.

\section{REFERENCES}

[1] Anthony Giddens. The constitution of society: Outline of the theory of structuration, volume 349. Univ of California Press, 1986.

[2] Karim Hussein, James Sumberg, and David Seddon. Increasing violent conflict between herders and farmers in Africa: claims and evidence. Development Policy Review, 17(4):397-418, 1999.

[3] AB Migliano, AE Page, J Gómez-Gardeñes, GD Salali, S Viguier, M Dyble, J Thompson, Nikhill Chaudhary, D Smith, J Strods, et al. Characterization of hunter-gatherer networks and implications for cumulative culture. Nature Human Behaviour, 1(2):0043, 2017.

[4] Mark Moritz. Understanding herder-farmer conflicts in West Africa: Outline of a processual approach. Human Organization, pages 138-148, 2010.

[5] Ningchuan Xiao, Shanshan Cai, Mark Moritz, Rebecca Garabed, and Laura W Pomeroy. Spatial and temporal characteristics of pastoral mobility in the far north region, Cameroon: data analysis and modelling. PloS One, 10(7):e0131697, 2015. 